\title{
Nitrogen balance of very preterm infants with extrauterine growth restriction
}

\author{
Rong $\mathrm{Wu}^{1 \#}$, Li-hua $\mathrm{Li}^{\# 2}$, Zhao-fang Tian" ${ }^{\# 3}$, Wen-ying $\mathrm{Xu}^{\# 1}$, Jin-hui Hu${ }^{\# 1}$, Ying-ying Liu ${ }^{1}$ \\ ${ }^{1}$ Neonatal Medical Center, Huaian Maternity and Child Healthcare Hospital, Yangzhou University. No.104, South Renmin \\ Road, Huaian; ${ }^{2}$ Department of Pediatrics, Beijing Luhe Hospital, Capital Medical University, Beijing; ${ }^{3}$ Department of \\ Neonatology, Huaian First People's Hospital, Nanjing Medical University, Huaian, China. E-mail:wr618@163.com \\ Received: 24th October 2017, Revised: 4th December 2017, 7th January 2018, Accepted: 16th January 2018 \\ ${ }^{*}$ Contribute equally to this work
}

SUMMARY: Wu R, Li LH, Tian ZF, Xu WY, Hu JH, Liu YY. Nitrogen balance of very preterm infants with extrauterine growth restriction. Turk J Pediatr 2019; 61: 352-358.

The aim of this study was to investigate the changes of nitrogen balance in preterm infants with extrauterine growth restriction (EUGR) during hospitalization. A total of 64 very preterm infants admitted to the Neonatal Medical Center of Huai'an Maternity and Child Healthcare Hospital were enrolled from May to October 2014. These infants had gestational ages less than 32 weeks and were within 24 hours after birth. The enrolled infants were classified into EUGR $(n=18)$ and non EUGR $(n=46)$ groups according to the discharge weight being below or above the 10th percentile of the expected intrauterine growth for the postmenstrual age. The urinary urea nitrogen of the infants were assayed by the Kjeldahl method and determined at 1st, 7 th, 14th and 28th day after birth. Nitrogen balance at each time point was calculated and compared between the EUGR and non EUGR groups. The incidence rate of small for gestational age (SGA) infants $(33.3 \%$ vs $0.0 \%)$ in the EUGR group was higher than that in non EUGR group. The difference was statistically significant $(\mathrm{p}<0.05)$. The birth weight $(1.37 \pm 0.20$ vs $1.63 \pm 0.27)$ and birth weight $Z$-score (-1.14 \pm 0.29 vs- $0.37 \pm 0.66)$ in the EUGR group were lower those in non EUGR group. The difference was statistically significant (all $\mathrm{p}<0.05$ ). At the $1 \mathrm{st}, 7 \mathrm{th}, 14$ th and 28 th day after birth, nitrogen balance values of all infants were negative, showing an upward trend with age. At each observation time point, the nitrogen balance values in the EUGR group were lower than those in non-EUGR group. The differences on the 1st and 28th day between two groups were statistically significant (both $\mathrm{p}<0.05$ ), while those on the other time point were not statistically significant (both $p>0.05$ ). All very preterm infants of study were in negative nitrogen balance while the infants of EUGR group had more seriously negative balance.

Key words: nitrogen balance, extrauterine growth restriction, very preterm, infant.

Extrauterine growth restriction (EUGR) means that the preterm infants did not achieve the expected growth in the uterus after birth and is defined as a growth measurement (weight, length, or head circumference) that is $\leq 10$ th percentile of the expected intrauterine growth for the postmenstrual age at the time of discharge. ${ }^{1}$ EUGR is a major clinical problem for preterm infants, especially critically ill preterm neonates. Malnutrition in the neonatal intensive care unit remains common. ${ }^{2}$ Early aggressive nutrition support is advantageous for physical and intellectual development in preterm infants, and reduces the incidence of EUGR. ${ }^{3-4}$ The nitrogen balance can reflect the level of amino acid and protein metabolism in vivo. ${ }^{5}$ In this study, all enrolled preterm infants were accepted with the nutritional support scheme of the Chinese guideline for newborn nutrition support. ${ }^{6}$ 
The aim of this study was to investigate the changes of nitrogen balance in preterm infants with EUGR during hospitalization.

\section{Material and Methods}

\section{Subjects}

This study was performed at the Neonatal Medical Center of Huai' an Maternity and Child Healthcare Hospital, after the local ethical committee's approval (Approval date is March 20, 2014. Number: 2014016) and parents of the preterm infants were informed about the nature of the study and written consents were obtained. From May 2014 to October 2014, a total of 64 preterm infants were enrolled. These infants met the following conditions: 1) gestational age $\leq 32$ weeks; 2) admission age $<24$ hours; 3 ) hospital days $\geq 2$ weeks; 3) meet with the discharge standard when discharged; 4) completed medical records. Exclusion criteria included lethal congenital anomalies, congenital inherited metabolic diseases, treated by surgical operation and infants born to mothers with severe endocrine and / or metabolic diseases.

\section{Study design}

The study was a prospective study. The enrolled infants were divided into EUGR group $(n=18)$ and non-EUGR group $(n=46)$ according to the discharge weight being below or above 10th percentile of the expected intrauterine growth for the postmenstrual age. ${ }^{1}$ The sample size was determined by the number of preterm infants (who met the above mentioned conditions) admitted to our hospital in six months.

\section{Parenteral and enteral nutrition support}

The nutritional schedules of all enrolled infants were carried out according to the Chinese guidelines for newborn nutrition support in neonates. ${ }^{6}$ Intravenous nutrition was given to the preterm infants in a few hours after birth. The initial dose of amino acid was $1.5 \sim 2 \mathrm{~g} / \mathrm{kg} / \mathrm{d}$, increased by $1 \mathrm{~g} / \mathrm{kg} / \mathrm{d}$ and quickly reached $3.5 \sim 4 \mathrm{~g} / \mathrm{kg} / \mathrm{d}$; the initial dose of fat emulsion was $1 \mathrm{~g} / \mathrm{kg} / \mathrm{d}$ and increased by $0.5 \sim 1 \mathrm{~g} / \mathrm{kg} / \mathrm{d}$ per day till $3.5 \mathrm{~g} / \mathrm{kg} / \mathrm{d}$; the initial dose of glucose was $4 \sim 8 \mathrm{mg} / \mathrm{kg} / \mathrm{min}$ and increased by $1 \sim 2 \mathrm{~g} / \mathrm{kg} / \mathrm{d}$ per day till $11 \sim 14$ $\mathrm{g} / \mathrm{kg} / \mathrm{d}$. The concentration of amino acid and fat emulsion were $6 \%$ and $20 \%$. Enteral feed refers to supply nutrients, such as breast milk and Human Milk Fortifier (HMF) through the stomach and intestine. When the amount of breast milk is up to $50 \mathrm{ml} / \mathrm{kg} / \mathrm{d}$, HMF is started at the half dose and increased up to full dose.

\section{Body weight measurement}

In the morning, before feeding and after changing diapers, the body weight of each preterm infant was measured by trained neonatal nurse. Weighing scale was a medical baby electric balance (measurement accuracy $\pm 10 \mathrm{~g}$ ).

\section{Urine collection}

The urine of the preterm infants for 24 hours was collected at the 1st, 7th, 14th and 28th day after birth. The $5 \mathrm{ml}$ urine was taken out and stored at $80^{\circ} \mathrm{C}$. Disposable infant urine collectors (Rehabilitation medical factory supplies, Zhejiang) were used to collect urine.

\section{Calculation for nitrogen balance values}

The urinary urea nitrogen (UUN) of the preterm infants was measured within 24 hours by Kjeldahl method. Total protein intakes (parenteral and enteral) were recorded each day. The 24-hour nitrogen balance value was calculated using the following formula:

Nitrogen balance value $(\mathrm{mg} / \mathrm{kg} \cdot \mathrm{d})=$ (protein intake/6.25) $-(\mathrm{UUN}+3)$

The protein intake includes total parenteral and enteral nutrition, divided by 6.25 , which is gram of nitrogen; constant 3 stands for loss urea nitrogen derived from fecal and non urine. UUN $=$ urine volume in 24 hours $(\mathrm{L}) \times$ concentration of Urine nitrogen $(\mathrm{mg} / \mathrm{L}){ }^{7}$

\section{Calculation for growth indicator}

Weight loss rate refers to physiological weight loss. The formula is:

Weight loss rate $=$ Birth weight - Minimum weight / birth weight $\times \%$.

Velocity of weight gain refers to average weight growth rate after birth weight recovery. The formula is: 
Average daily body weight gain $(\mathrm{g} / \mathrm{kg} / \mathrm{d})=$ Discharge weight - Birth weight / hospital days.

Weight Z-score of preterm infants was calculated by the formula:

Weight Z-score $=$ (actual body weight - the average of the gestational weight) / standard deviation of the weight for gestational age. ${ }^{8}$

\section{Statistical analysis}

The data were analyzed using SSPS v.18.0 software (IBM Corp., Chicago, IL, USA). The data were described using mean values and S.D. or rate and percentage. The differences of variables, which have been confirmed as normal distributions, were analyzed between two groups with the Student's t test. Differences of Count data between two groups were analyzed with chi-square test and Fisher exact probability. The linear change among the EUGR group and the non-EUGR group at all of the time points were analyzed by repeated measures analysis of variance. Lastly, a p value $<0.05$ was considered statistically significant.

\section{Results}

\section{Baseline characteristics in the two study groups}

Sixty four preterm infants were involved in the study. The incidence rate of small for gestational age (SGA) infants $(33.3 \%$ vs $0.0 \%$ ) in the EUGR group was higher than that in non EUGR group, the difference was statistically significant $(\mathrm{p}<0.05)$. The birth weight $(1.37 \pm 0.20$ vs $1.63 \pm 0.27)$ and birth weight $Z$-score $(-1.14 \pm 0.29$ vs- $0.37 \pm 0.66)$ in the EUGR group was lower than that in non EUGR group, the difference was statistically significant (all $\mathrm{p}<0.05$ ). All the other parameters showed no significant difference between the two study groups (All $\mathrm{p}>0.05$ ). These can be seen in Table I.

\section{The indicators of nutritional intake and growth in the two study groups}

The time of amino acid usage, initial amino acid dosage, time of fat emulsion usage, time of full enteral feeding and cumulative calories of intravenous nutrition during hospitalization in the EUGR group were higher than those in the non EUGR group, the differences were statistically significant (all p $<0.05$ ). All the other indicators showed no significant difference between the two study groups (All $\mathrm{p}>0.05)$. These can be seen in Table II.

\section{The nitrogen balance scores in the two study groups at different time points}

At the 1st, 7th, 14th and 28th day after birth, nitrogen balance values of all infants were negative, showing an upward trend with age. The linear comparison of nitrogen balance values between the two study groups at all of time points was significantly different $(\mathrm{F}=16.083, \mathrm{p}=0.000)$. At the 1 st and 28 th day, the nitrogen balance values of the EUGR group were lower than those of non EUGR group, the differences were statistically significant (both $\mathrm{p}<0.05)$. At the 7 th and 28 th day, there was no significant difference between the nitrogen balance values of the two study groups (both $\mathrm{p}$ $>0.05)$. These can be seen in Table III.

\section{Discussion}

EUGR has existed as a serious problem frequently occurring in preterm infants hospitalized in the neonatal intensive care unit for many years. Currently, in spite of improvements in nutritional support of preterm infants through aggressive and early parenteral and enteral nutrition, EUGR remains a universal phenomenon. ${ }^{9-11}$ Shan et al. ${ }^{12}$ analyzed 2,015 preterm infants with low birth weight born at four hospitals in Shanghai and found a frequency of $56.8 \%$ of EUGR for weight. In this study, the incidence rate of EUGR for weight was $28.1 \%$ (18/64) which was lower than that of the above study. The current trend is to avoid, wherever possible, EUGR through early, aggressive parenteral nutrition (with nutrients similar to those the fetus would receive through the placenta) and enteral feeding as early as possible. ${ }^{13}$ Nutritional care of the prematurely born low birth weight infant, aimed at achieving intrauterine rate of growth and nitrogen accretion, continues to be a major challenge for the clinical neonatologist.

One study by logistic regression found that male gender, gestational age at birth, birth weight, length of hospital stay and nutrition 
Table I. Baseline Characteristics in the Two Study Groups.

\begin{tabular}{|c|c|c|c|c|}
\hline Characteristics $\backslash$ Group & $\begin{array}{l}\text { EUGR group } \\
(\mathrm{n}=18)\end{array}$ & $\begin{array}{l}\text { Non EUGR group } \\
(n=46)\end{array}$ & $X^{2} / \mathrm{t}$ & $P$ \\
\hline Male (n, \%) & $10(55.6)$ & $32(69.6)$ & 0.133 & 0.737 \\
\hline VLBW (n, \%) & $12(66.7)$ & $16(34.8)$ & 1.534 & 0.216 \\
\hline Incidence of SGA (n, \%) & $6(33.3)$ & $0(0.0)$ & - & $0.025^{\wedge}$ \\
\hline Gestational age at birth (W) & $31.22 \pm 1.00$ & $30.76 \pm 1.04$ & 1.139 & 0.264 \\
\hline Gestational age at discharge (W) & $36.70 \pm 1.03$ & $35.60 \pm 2.06$ & 1.532 & 0.138 \\
\hline Birth weight (kg) & $1.37 \pm 0.20$ & $1.63 \pm 0.27$ & 2.681 & 0.012 \\
\hline Discharge weight $(\mathrm{kg})$ & $2.16 \pm 0.17$ & $2.39 \pm 0.35$ & 1.846 & 0.075 \\
\hline weight Z-score at birth & $-1.14 \pm 0.29$ & $-0.37 \pm 0.66$ & 3.329 & 0.002 \\
\hline Hospitalization days (d) & $38.00 \pm 10.06$ & $33.87 \pm 16.64$ & 0.692 & 0.494 \\
\hline NRDS $(n, \%)$ & $6(33.3)$ & $20(43.5)$ & - & $0.900^{\wedge}$ \\
\hline $\operatorname{PDA}(\mathrm{n}, \%)$ & $2(11.1)$ & $2(4.3)$ & - & $1.000^{\wedge}$ \\
\hline $\mathrm{ROP}(\mathrm{n}, \%)$ & $4(22.2)$ & $0(0.0)$ & - & $0.128^{\wedge}$ \\
\hline $\mathrm{BPD}(\mathrm{n}, \%)$ & $2(11.1)$ & $6(13.0)$ & - & $1.000^{\wedge}$ \\
\hline Sepsis $(n, \%)$ & $12(66.7)$ & $18(39.1)$ & 1.019 & 0.313 \\
\hline Moderate to severe anemia $(\mathrm{n}, \%)$ & $12(66.7)$ & $32(69.6)$ & 0.000 & 1.000 \\
\hline Birth asphyxia (n, \%) & $2(11.1)$ & $8(17.4)$ & - & $1.000^{\wedge}$ \\
\hline Twins (n, \%) & $8(44.4)$ & $18(39.1)$ & - & $1.000^{\wedge}$ \\
\hline Premature rupture of membranes $(n, \%)$ & $8(44.4)$ & $12(26.1)$ & - & $0.560^{\wedge}$ \\
\hline pregnancy-induced hypertension (n, \%) & $2(11.1)$ & $0(0.0)$ & - & $0.621^{\wedge}$ \\
\hline Placental abruption (n, \%) & $0(0.0)$ & $2(4.3)$ & - & $1.000^{\wedge}$ \\
\hline Advanced maternal age (n, \%) & $0(0.0)$ & $6(13.0)$ & - & $0.643^{\wedge}$ \\
\hline
\end{tabular}

^: For Fisher test. VLBW: Very low birth weight infant. EUGR: Extrauterine growth restriction. SGA: Small for gestational age. NRDS: Neonatal respiratory distress syndrome. PDA: Patent ductus arteriosus. ROP: Retinopathy. BPD: Bronchopulmonary dysplasia.

support team availability were risk factors of EUGR. ${ }^{12}$ Lima PA et al. ${ }^{14}$ analyzed 570 very low birth weight infants in Rio de Janeiro and found extrauterine growth restriction was high in the population, especially for SGA newborns and those with neonatal morbidities. In this study, we found the birth weight and birth weight Z-score in the EUGR group were lower than those in non EUGR group ( $p<0.05)$, and the EUGR group had $1 / 3$ of SGA infants whereas the non EUGR group there were no SGA ( $\mathrm{p}<$ $0.05)$. These results support the conclusions of the above studies.

Recent reports that have demonstrated that aggressive nutritional regimes of early parenteral and enteral nutritional support can be safely provided to critically ill very low birth weight infants and are associated with improved growth, without increased risks or adverse clinical outcomes. ${ }^{15-17}$ In this study, we carried out early nutritional management. Birth weight and birth weight $\mathrm{Z}$-scores were lower and also the incidence of SGA infants was higher in the EUGR group than those in non EUGR group. However, there was no significance difference in weight loss rate, the velocity of weight gain, discharged weight Z-score, and the other indexes about growth and development between EUGR group and non EUGR group. The reason might be that the time of amino acid usage and fat emulsion usage, initial amino acid dosage, time of full enteral feeding and cumulative calories of intravenous nutrition during hospitalization in the EUGR group were higher than those in the non EUGR group. 
Table II. Comparison of the Indicators of Nutritional Intake and Growth in the Two Study Groups.

\begin{tabular}{|c|c|c|c|c|}
\hline Indicators $\backslash$ Group & $\begin{array}{l}\text { EUGR group } \\
(\mathrm{n}=18)\end{array}$ & $\begin{array}{l}\text { Non EUGR group } \\
(\mathrm{n}=46)\end{array}$ & $\mathrm{t}$ & $P$ \\
\hline Time of first use amino acid (d) & $1.11 \pm 0.33$ & $1.04 \pm 0.21$ & 0.694 & 0.493 \\
\hline Time of amino acid usage (d) & $27.22 \pm 5.70$ & $18.57 \pm 8.51$ & 2.803 & 0.009 \\
\hline Initial amino acid dosage (g/Kg.d) & $2.19 \pm 0.38$ & $1.88 \pm 0.34$ & 0.883 & 0.035 \\
\hline Cumulative use of amino acids $(\mathrm{g} / \mathrm{d})$ & $3.02 \pm 0.68$ & $2.98 \pm 0.58$ & 0.152 & 0.880 \\
\hline Time of first use fat emulsion (d) & $1.89 \pm 0.33$ & $2.04 \pm 0.47$ & 0.891 & 0.380 \\
\hline Time of fat emulsion usage $(\mathrm{d})$ & $24.33 \pm 5.94$ & $16.74 \pm 8.37$ & 2.478 & 0.019 \\
\hline Initial fat emulsion dosage (g/Kg.d) & $1.57 \pm 0.63$ & $1.44 \pm 0.37$ & 0.736 & 0.467 \\
\hline Cumulative use of fat emulsion $(\mathrm{g} / \mathrm{d})$ & $3.75 \pm 0.66$ & $4.10 \pm 0.77$ & 1.193 & 0.242 \\
\hline $\begin{array}{l}\text { Cumulative calories of intravenous } \\
\text { nutrition in first week(Kcal) }\end{array}$ & $635.97 \pm 66.93$ & $679.73 \pm 110.52$ & 1.105 & 0.278 \\
\hline $\begin{array}{l}\text { Cumulative calories of intravenous } \\
\text { nutrition in first } 2 \text { weeks (Kcal) }\end{array}$ & $1379.15 \pm 197.20$ & $1270.30 \pm 277.67$ & 1.070 & 0.293 \\
\hline $\begin{array}{l}\text { Cumulative calories of intravenous } \\
\text { nutrition during hospitalization (Kcal) }\end{array}$ & $2665.05 \pm 967.71$ & $1787.03 \pm 886.16$ & 2.458 & 0.020 \\
\hline Start enteral feeding time $(\mathrm{d})$ & $4.11 \pm 2.26$ & $3.91 \pm 2.43$ & 0.211 & 0.834 \\
\hline Time of full enteral feeding (d) & $28.22 \pm 5.67$ & $19.61 \pm 8.58$ & 2.777 & 0.010 \\
\hline $\begin{array}{l}\text { Time of parenteral nutrition up to } 100 \\
\text { Kcal/Kg.d (d) }\end{array}$ & $21.89 \pm 7.56$ & $18.57 \pm 8.88$ & 0.989 & 0.330 \\
\hline Birth weight recovery time $(\mathrm{d})$ & $7.22 \pm 1.99$ & $7.30 \pm 2.57$ & 0.086 & 0.932 \\
\hline Weight loss rate (\%) & $0.06 \pm 0.02$ & $0.05 \pm 0.02$ & 0.187 & 0.853 \\
\hline average daily body weight gain $(\mathrm{g} / \mathrm{kg} / \mathrm{d})$ & $15.12 \pm 3.41$ & $15.11 \pm 3.99$ & 0.001 & 0.999 \\
\hline Discharged weight Z-score & $-1.16 \pm 0.77$ & $-1.01 \pm 0.62$ & 0.593 & 0.557 \\
\hline
\end{tabular}

EUGR: Extrauterine growth restriction.

Table III. Comparison of Nitrogen Balance Values in the Two Study Groups at Different Time Points.

\begin{tabular}{|c|c|c|c|c|c|c|}
\hline Group & $1^{\text {st }}$ day after birth & $7^{\text {th }}$ days after birth & $14^{\text {th }}$ days after birt & $28^{\text {th }}$ days after birth & $F$ & $P$ \\
\hline $\begin{array}{l}\text { EUGR group } \\
(\mathrm{n}=18)\end{array}$ & $-492.66 \pm 204.39$ & $-290.79 \pm 173.78$ & $-205.96 \pm 180.59$ & $-145.14 \pm 140.15$ & 53.086 & 0.000 \\
\hline $\begin{array}{l}\text { Non EUGR } \\
\text { group }(n=46)\end{array}$ & $-383.41 \pm 130.57$ & $-278.91 \pm 225.80$ & $-182.00 \pm 144.70$ & $-61.08 \pm 49.71$ & 41.745 & 0.000 \\
\hline$t$ & 2.546 & 0.201 & 0.555 & 2.484 & & \\
\hline$P$ & 0.013 & 0.842 & 0.581 & 0.023 & & \\
\hline
\end{tabular}

EUGR: Extrauterine growth restriction.

Protein is an indispensable component of tissue cells, involved in the renewal and repair/regeneration and repair of it. When the energy supply is insufficient, it will increase the decomposition of protein. Body protein synthesis depends on the amount of intestinal amino acid absorption and regulated synchronously with sensing of the concentration of extracellular amino acid. ${ }^{18-19}$

Preterm infants need to be fed enough amino acids and protein, starting right after birth, to prevent protein breakdown and to promote the growth and remodeling of cells, tissues, and organs at rates and producing body composition of lean body mass that mimic 
the growth and body composition of healthy fetuses growing in utero. This means providing amino acids and proteins earlier and in greater amounts after birth than customarily have been provided. ${ }^{20}$ Nitrogen balance represents the level of protein metabolism. Since very preterm infants are sick during the immediate period after birth due to acute respiratory distress and vascular instability, require significant clinical support, and are often receiving vasopressor agents, they are in a "catabolic" state and have negative nitrogen balance. ${ }^{21}$ Our study showed that birth weights of EUGR group were lower than those of non EUGR group $(p<0.05)$, the nitrogen balance values at each time point were higher than those in the non EUGR group, the difference was statistically significant at the 1 st and 28th day after birth (all p < 0.05) and the linear comparison of nitrogen balance values between the two study groups at all of time points was significantly different $(\mathrm{p}<0.05)$. These results indicated that the lower the birth weight, the greater requirement of nitrogen, so the infants with a lower birth weight were associated with greater values of negative nitrogen balance.

The data from the US National Institutes of Health Eunice Kennedy Shriver National Institute of Child Health and Development Neonatal Research Network show that preterm infants of nearly all early gestational ages still show postnatal growth delays. This is especially true for the smallest, most preterm infants who are taking longer and longer to start growing after their preterm birth, achieve normal rates of growth, and reach normal body size, even at term gestational age. ${ }^{22}$ In the study, we found that all enrolled very preterm infants were in a state of negative nitrogen balance during hospitalization. These results indicated that the very preterm infants were limited in receiving nonprotein calorie and were in a state of protein decomposition greater than synthesis. These results supported the view that increasing of body weight of preterm infants is not the best measure of nutritional success, as it ignores changes in body composition, and cell and organ development and function. ${ }^{21}$ So, we should explore the true nutritional needs of preterm infants to optimize their growth and development.
In summary, our results showed that the very preterm infants were in a state of negative nitrogen balance during hospitalization and the EUGR infants had more severe negative nitrogen balance. The limitations of this study are that the nitrogen balance status of preterm infants could not be assessed by a method of radioactive isotope tracer dynamics and the number of cases in this study is small. A larger sample and multicenter studies are required.

\section{Acknowledgements}

We thank all the neonatal units and staff who responded to our survey. This research was funded by Science and Technology Program of Huaian City (Project no: HAS2015004).

\section{REFERENCES}

1. Clark RH, Thomas P, Peabody J. Extrauterine growth restriction remains a serious problem in prematurely born neonates. Pediatrics 2003; 111(5Pt 1): 986-990.

2. Clark RH, Wagner CL, Merritt RJ, et al. Nutrition in the neonatal intensive care unit: How do we reduce the incidence of extrauterine growth restriction? J Perinatol 2003; 23: 337-344.

3. Thureen PJ, Hay WW Jr. Early aggressive nutrition in preterm infants. Semin Neonatal 2001; 6: 403-415

4. Dusick AM, Poindexter BB, Ehrenkranz RA, Lemons JA. Growth failure in the preterm infant: Can we catch up?. Semin Perinatal 2003; 27: 302-310.

5. Kalhan SC, Bier DM. Protein and amino acid metabolism in the human newborn. Annu Rev Nutr 2008; 28: 389-410.

6. The group of Pediatrics, Society of Parenteral and Enteral Nutrition, Chinese Medical Association. The group of Neonatology, Society of Pediatrics, Chinese Medical Association. Chinese guideline for newborn nutrition support in neonates. Zhonghua Xiaoer Waike Zazhi 2013; 34: 782-787.

7. Blackburn GL, Bistrian BR, Maini BS, Schlamm HT, Smith MF. Nutritional and metabolic assessment of the hospitalized patient. JPEN J Parenter Enteral Nutr 1977; 1: 11-22.

8. Wu R, Li LH, Xue LJ, Xu WY, Tian ZF. The value of use of $\mathrm{Z}$-score as a predictor of prognosis of the extrauterine growth restriction. Biomed Res 2017; 28: 5836-5840.

9. Agostoni C, Buonocore G, Carnielli VP, et al ESPGHAN Committee on Nutrition. Enteral nutrient supply for preterm infants: Commentary from the European Society of Paediatric Gastroenterology Hepatology and Nutrition Committee on Nutrition. J Pediatr Gastroenterol Nutr 2010; 50: 85-91. 
10. Stoll BJ, Hansen NI, Bell EF, et al; Eunice Kennedy Shriver National Institute of Child Health and Human Development Neonatal Research Network. Neonatal outcomes of extremely preterm infants from the NICHD Neonatal Research Network. Pediatrics 2010; 126: 443-456.

11. Cole TJ, Statnikov Y, Santhakumaran S, Pan H, Modi $\mathrm{N}$; Neonatal Data Analysis Unit and the Preterm Growth Investigator Group. Birth weight and longitudinal growth in infants born below 32 weeks' gestation: A UK population study. Arch Dis Child Fetal Neonatal Ed 2014; 99: F34-F40.

12. Shan HM, Cai W, Cao Y, Fang BH, Feng Y. Extrauterine growth retardation in premature infants in Shanghai: A multicenter retrospective review. Eur J Pediatr 2009; $168:$ 1055-1059.

13. Espinosa Fernandez MG, Sanchez-Tamayo T, Moreno Algarra MC, et al. New clinical practice guideline on enteral feeding in very low birth weight infants; second part. Nutr Hosp 2014; 30: 329-337.

14. Lima PA, Carvalho Md, Costa AC, Moreira ME. Variables associated with extra uterine growth restriction in very low birth weight infants. J Pediatr (Rio J) 2014; 90: 22-27.

15. Ehrenkranz RA, Das A, Wrage LA, et al; Eunice Kennedy Shriver National Institute of Child Health and Human Development Neonatal Research Network. Early nutrition mediates the influence of severity of illness on extremely LBW infants. Pediatr Res 2011; 69: 522-529.
16. Franz AR, Pohlandt $\mathrm{F}$, Bode $\mathrm{H}$, et al. Intrauterine, early neonatal, and postdischarge growth and neurodevelopmental outcome at 5.4 years in extremely preterm infants after intensive neonatal nutritional support. Pediatrics 2009; 123: e101-e109.

17. Stephens BE, Walden RV, Gargus RA, et al. Firstweek of protein and energy intakes are associated with 18-month developmental outcomes in extremely low birth weight infants. Pediatrics 2009; 123: 1337 1343.

18. Wang WW, Qiao SY, Li DF. Amino acids and gut function. Amino Acids 2009; 37: 105-110.

19. Hietakangas V, Cohen SM. Regulation of tissue growth through nutrient sensing. Annu Rev Genet 2009; 43: 389-410.

20. Hay WW, Thureen P. Protein for preterm infants: How much is needed? How much is enough? How much is too much? Pediatr Neonatal 2010; 51: 198-207.

21. Kalhan SC, Edmison JM. Effect of intravenous amino acids on protein kinetics in preterm infants. Curr Opin Clin Nutr Metab Care 2007; 10: 69-74.

22. Ehrenkranz RA, Younes N, Lemons JA, et al Longitudinal growth of hospitalized very low birth weight infants. Pediatrics 1999; 104(2 Pt 1): 280-289. 